\title{
RT-PCR Assay for Detection of Enterotropic Strains of Mouse Hepatitis Virus in Faecal Samples
}

\author{
M.R. Srinivasan¹, K. Vijay, A.K. Karuppannan, S. Ramesh¹, Y. Krishnamohan Reddy
}

10.18805/IJAR.B-4257

\begin{abstract}
Background: Mouse Hepatitis Virus (MHV) is one of the most important and common viral infections of laboratory mice, due to its highly contagious and subclinical nature, posing threat to the research outcomes. Periodic screening of laboratory mice for MHV is mandatory. Hence, this study was intended to develop sensitive faecal based RT-PCR assays to detect active infection of enterotropic MHV in laboratory mice.

Methods: Primers targeting N-gene of MHV were selected and their sensitivity was analysed in tenfold serially diluted gene template in the presence of negative mouse faecal cDNA. Thirty-six weaned mice at the age of 6 to 18 weeks were randomly selected at different periods and the blood and faecal sample were collected for serology and RT-PCR assay respectively. RT-PCR assay in colon samples was carried out for comparison.

Result: PCR assay of MHV detected as low as $4 \mathrm{fg}$ of plasmid DNA. Seroprevalence of MHV is very high than the prevalence by RT$P C R$ assay showing its retrospective nature and also seroprevalence includes both enterotropic and polytropic strain. RT-PCR results in faecal samples are analogous with that of the colon samples, showing the reliability of antemortem testing of mice for enterotropic strain of MHV.
\end{abstract}

Key Words: Faecal RT-PCR, Health monitoring, Mouse hepatitis virus.

\section{INTRODUCTION}

Laboratory animals are used in various biomedical research. The data obtained from those researches should be reliable, accurate and unbiased for its relevance in animal or human explorations and its impact on animal or human health (Kohale and Raut, 2013). In the course of housing in colonies, laboratory animals are prone to develop infections caused by various viruses (Elizebath et al. 2012). MHV remains one of the most important viral infections of laboratory mice. Numerous surveys confirmed its high seroprevalences due to its highly contagious nature. However it causes infections of subclinical nature without overt clinical signs and influences physiological and pharmacological parameters in laboratory mice, thus potentially influencing the outcome of the research (Nicklas et al. 1999). MHV is categorized into enterotropic strain, restricted to the gastrointestinal tract and polytropic strain, restricted to the upper respiratory tract. Among these, enterotropic infections are the most common form of natural infection (Yamada et al. 1998).

ELISA is the common serological method for the detection of the prevalence of MHV in laboratory mice. However, it cannot detect early infection, induction of antibody response requires 10-14 days post-infection and it cannot be applied to immunodeficient animals (Wan et al. 2006). It is also prohibitively costly for the government academic institutions in India.

While serological methods are not applicable, direct detection of viral nucleic acid is a better alternate. RT-PCR
Centre for Animal Health Studies, Tamil Nadu Veterinary and Animal Sciences University, Chennai-600 051, Tamil Nadu, India. 'Department of Veterinary Pharmacology and Toxicology, Madras Veterinary College, Vepery, Chennai-600 007, Tamil Nadu, India.

Corresponding Author: K. Vijay, Centre for Animal Health Studies, Tamil Nadu Veterinary and Animal Sciences University, Chennai600 051, Tamil Nadu, India. Email: vijayvet88@gmail.com

How to cite this article: Srinivasan, M.R., Vijay, K., Karuppannan, A.K., Ramesh, S. and Reddy, Y.K. (2021). RT-PCR Assay for Detection of Enterotropic strains of Mouse Hepatitis Virus in Faecal Samples. Indian Journal of Animal Research. ():

DOI: $10.18805 /$ IJAR.B-4257.

Submitted: 21-07-2020 Accepted: 09-12-2020 Online: 02-02-2021

is a rapid and sensitive method in the diagnosis of infections and it has been found effective in the detection of MHV in faecal and tissue samples of experimentally infected mice and in natural outbreaks in immunodeficient mice (Yamada et al. 1998). Given that 3R's principle, RT-PCR in faecal samples is a promising tool due to easy sample collection, less stress to the animals and antemortem testing (Bauer and Riley, 2006) is preferable over post-mortem testing in valuable animals.

Hence this study was planned to develop a sensitive faecal based RT-PCR assay to detect the natural outbreaks of enterotropic strains of MHV in laboratory mice as an alternate approach to serology based health monitoring in a lab animal breeding unit. 
RT-PCR Assay for Detection of Enterotropic strains of Mouse Hepatitis Virus in Faecal Samples

\section{MATERIALS AND METHODS}

\section{Animal maintenance}

We performed the study with thirty-six weaned Swiss albino mice (SAM) of 6 to 18 weeks at the Laboratory Animal Medicine Unit - a breeding unit of Tamil Nadu Veterinary and Animal Sciences University (TANUVAS). We carried out the study after the approval of the institutional animal ethical committee (IAEC), MVC, Chennai-07 (IAEC No. 172/DFBS/B/ 2013 dated 17.10.2013) and as per the guidelines of the Committee for the Purpose of Control and Supervision of Experimentation in Animals (CPCSEA) Ministry of Environment, Forest and Climate Change, Government of India.

Mice were maintained in polypropylene cages with Corn Cobb bedding material and supplied with ad libitum feed and water. Cages, bedding materials and water bottles were autoclaved and purified water by Reverse Osmosis method and autoclaved before it was kept in each cage. Animals were maintained at room temperature $22 \pm 3^{\circ} \mathrm{C}$ and relative humidity $50 \pm 10 \%$ and ventilated with centralized air conditioning by the HVAC system.

\section{Sample collection}

Anaesthetized the mice using $3 \%$ isoflurane using an isoflurane anaesthetic apparatus and collected blood samples from the lateral tail vein. Serum separated from clotted blood samples was stored as aliquots at $-20^{\circ} \mathrm{C}$. Fresh faecal samples were collected and were subjected to nucleic acid extraction immediately.

The animals were euthanized by carbon-dioxide asphyxiation with steady state of increasing the carbondioxide concentration in the chamber. Colon samples were collected from mice in a sterile container and stored at -80 ${ }^{\circ} \mathrm{C}$ until further use.

\section{Oligonucleotide primers}

The primers F5'- AGCAGACTGCAACTACTC-3' (as previously published by Homberger et al. 1998) and R5'- TAG CCT CAT GAC TGC TTG-3' flanked the region of 375 nucleotide long in highly conserved $\mathrm{N}$-gene of MHV. The Consensus sequence was generated after multiple alignments of Nucleocapsid (N) gene sequences of all the MHV strains using the DNASTAR Lasergene software. The reverse primer used in this study was designed by using the $\mathrm{NCBI}$ primer designing tool from the consensus sequence.

\section{Gene template}

Gene template containing the N-gene sequence of MHV was synthesised in the PUC57 vector by Genscript. Gene template sequence of MHV corresponds with the MCS region of the PUC57 cloning vector as shown in fig 1. Gene template was used as a positive control in all PCR assays and in the standardization of primers.

\section{Sensitivity}

The sensitivity of the primers was determined by using 10 fold serial dilution of purified plasmid vector containing gene sequence. To mimic diagnostic samples an equal volume containing 5 ng of mouse faecal cDNA (Negative for MHV) was added to reactions containing serially diluted plasmid DNA

\section{RT-PCR assay}

RNA was isolated from faecal samples of mice. Briefly, a single mouse faecal pellet was suspended in $2 \mathrm{~mL}$ of sterile Phosphate-buffered saline (PBS), $\mathrm{pH}$ 7.4. The suspension was centrifuged at $700 \times \mathrm{g}$ for $5 \mathrm{~min}$ at $4^{\circ} \mathrm{C}$. A $100 \mu \mathrm{L}$ of the supernatant of the centrifuged was diluted with PBS at the ratio of 1:2 (Beckwith et al. 1997) and this faecal mixture or tissue sample was used for RNA extraction as per the protocol described in catalogue using TRI Reagent (Sigma Catalog Number T9424). cDNA was synthesized as per the manufacturer's instructions using high capacity cDNA Reverse Transcription Kits (Applied biosystem catalog number 4368814).

PCR assays were performed with a final volume of 20 $\mu \mathrm{L}$, using $10 \mathrm{pmol}$ in $1 \mu \mathrm{L}$ of each primer, $5 \mathrm{ng}$ of template DNA or $2 \mu \mathrm{L}$ of synthesised cDNA, $10 \mu \mathrm{L}$ of ready to use Taq DNA polymerase $2 X$ master mix red (AMPLIQON, Denmark) and the final volume was adjusted with the nuclease free water. All PCR assays included positive and negative controls. An initial denaturation step of $95^{\circ} \mathrm{C}$ for 3 min followed by 40 cycles of denaturation at $95^{\circ} \mathrm{C}$ for $45 \mathrm{sec}$, annealing $57^{\circ} \mathrm{C}$ for $20 \mathrm{sec}$ and extension at $72^{\circ} \mathrm{C}$ for $1 \mathrm{~min}$ and a final extension at $72^{\circ} \mathrm{C}$ for $7 \mathrm{~min}$. Amplicons obtained from PCR reactions were subjected to electrophoresis on a $2 \%$ agarose gel. PCR amplified products were analysed by agarose gel electrophoresis in the $1.5 \%$ agarose gel (Containing Ethidium bromide $5 \mu \mathrm{g} / \mathrm{mL}$ of gel). Amplicon size was compared with molecular weight markers and visualized in the Bio-Rad gel documentation system.

\section{Serology}

Serum samples were analyzed by Sandwich ELISA using the available commercial kit (XpressBio Life Science Products, Thurmont, MD 21788, USA), for the presence or absence of antibody as per the protocol described by the manufacturer.

\section{RESULTS AND DISCUSSION}

The Sensitivity of MHV was determined by using 10 fold serial dilution of the plasmid template (Concentrations ranged from $400 \mathrm{pg}$ to $4 \mathrm{fg} / \mathrm{PCR}$ assay) and mouse faecal cDNA was also added at the concentration of 5 ng per assay (Negative for MHV). PCR assays consistently amplified as little as $4 \mathrm{fg}$ (Fig 2) of plasmid DNA.

Table 1 contains the results of RT-PCR (Fig 3) and serology performed in this study. In colon samples, 19 out of 36 samples were positive (53\%) and 16 out of 36 faecal samples (44\%) were PCR positive for MHV. Serology results showed 33 out of 36 animals (92\%) were positive for MHV. Diagnostic sensitivity and specificity were determined by considering serology results as true positive and true negative results (Kundave et al. 2017) and are shown in Table 1. Diagnostic sensitivity of MHV RT-PCR assay of the faecal samples is $49 \%$ and that of colon samples is $58 \%$. 
Table 1: showing results serology and RT-PCR, Diagnostic sensitivity and specificity.

\begin{tabular}{lccc}
\hline TEST & Sample positive & Diagnostic sensitivity & Diagnostic specificity $^{*}$ \\
\hline SEROLOGY & $33 / 36(92 \%)$ & $100 \%$ & $100 \%$ \\
RT-PCR in faeces & $16 / 36(44 \%)$ & $49 \%$ & $100 \%$ \\
RT-PCR in colon & $19 / 36(53 \%)$ & $58 \%$ & $100 \%$ \\
\hline
\end{tabular}

$\#$ is [No. of true positive / (No of true positive + No. of false negative)] $\times 100$.

"is [No. of true negative / (No of true negative + No. of false positive)] $\times 100$.

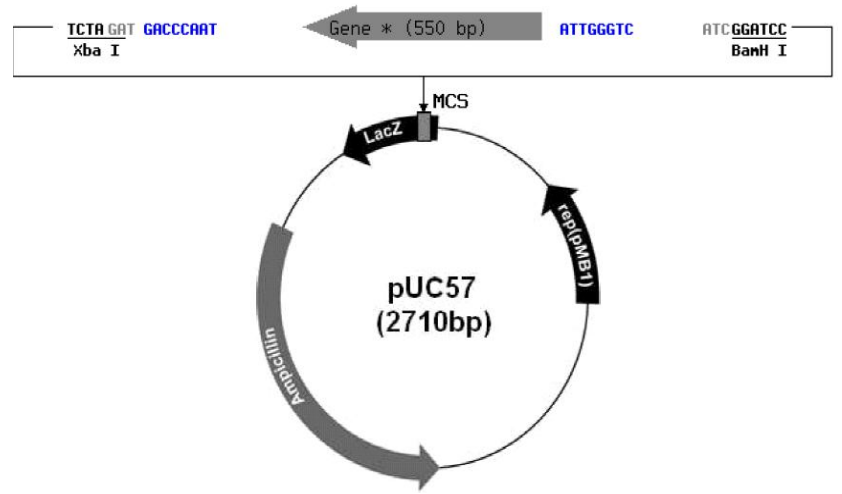

Fig 1: showing the gene template construct in PUC57 vector.

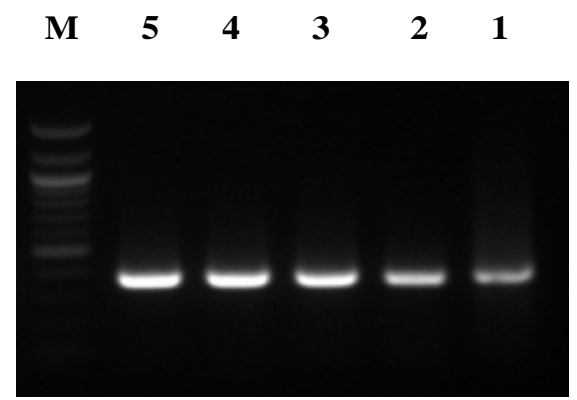

$375 \mathrm{bp}$

Fig 2: Ethidium bromide stained gel showing detection of sensitivity of RT-PCR assay of MHV; M- marker, 5- 40pg, 4- 4pg, 3- $400 \mathrm{fg}, 2-40 \mathrm{fg}, 1-4 \mathrm{fg}$ of positive plasmid DNA template with faecal DNA.

\section{$\begin{array}{lllllllll}\mathbf{N} & \mathbf{P} & \mathbf{1} & \mathbf{2} & \mathbf{3} & \mathbf{4} & \mathbf{5} & \mathbf{6} & \mathrm{M}\end{array}$}

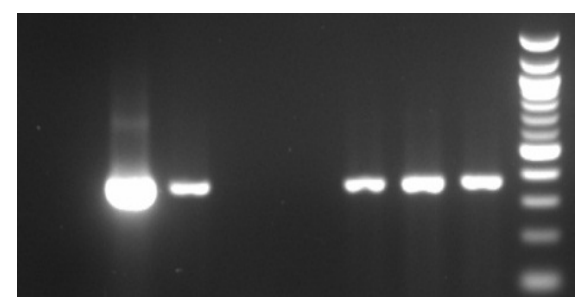

$375 \mathrm{bp}$

Fig 3: Ethidium bromide stained gel showing detection of MHV in samples. N- negative control, P- Positive control, M-marker, 1-3 - Faecal samples of mice and 4-6 - colon samples of mice.

Seronegative animals from the colony were all negative for MHV by RT-PCR showing its diagnostic specificity.

In the present study, the high prevalence rate of MHV by serology in natural cases may be due to the highly contagious nature of the virus (Pritchett-corning et al. 2009). MHV was detected in $44 \%$ of faecal samples and $53 \%$ of caecal samples which is far less than in serology. Thus low positive rate in PCR compared to ELISA may be due to rapid clearing of the virus by MHV antibodies produced in mouse (Wang et al. 1999) and animals that showed positive are all probably in the early and active phase of infection unlike serology which is retrospective in nature and increases in seroprevalence may also be due to polytropic strains (Pullium et al. 2003).

MHV shed in faeces and is detectable by RT-PCR as early as 4 days till 6 weeks post-infection (Scavizzi and Raspa, 2004). MHV is detected in 3 days through 21 days post-infection in experimental inoculation (Casebolt et al. 1992) and the excretion of virus in faeces continued for a longer period in immunodeficient animals and detectable till 3 months post-infection (Yamada et al. 1999). Choosing the correct time of sample collection during the outbreak plays a key role in diagnosis. During a natural outbreak, the excretion of virus continues for a longer period, as a small number of animals remaining susceptible are infected one after another (Yamada et al., 1999).

The Prevalence of MHV in natural outbreak by RT-PCR in faecal samples is $44 \%$ which is comparable with the findings of Yamada et al. (1999), who found that $54 \%$ of immunocompromised mice were positive in a natural outbreak. Comparison of Prevalence by RT-PCR in faecal and colon samples was comparable with the findings Wang et al. (1999). However, there was no study conducted to compare the results of serology with that of RT-PCR in faecal samples and colon samples in natural outbreaks.

\section{CONCLUSION}

The results of the prevalence study with RT-PCR and ELISA indicate that the faecal-PCR assays may be useful as a non-invasive diagnostic tool for the rapid detection of active MHV infection. Further evaluations of PCR sensitivity in comparisons of differences in mouse strains are essential.

\section{ACKNOWLEDGEMENT}

This work was funded by SERB, DST, Government of India. Thanks to the Directorate of Centre for Animal Health Studies, Tamil Nadu Veterinary and Animal Sciences University for the laboratory space and expert guidance for the conduct of the study.

\section{REFERENCES}

Bauer, B.A. and Riley, L.K. (2006). Antemortem detection of mouse parvovirus and mice minute virus by polymerase chain reaction (PCR) of faecal samples. Lab Anim. 40: 144-152. 
Beckwith, C.S., Franklin, C.L., Hook, R.R., Besch-willford, C.L. and Riley, L.K. (1997). Faecal PCR assay for diagnosis of Helicobacter infection in laboratory rodents. J. clin. Microbiol. 35(6): 1620-1623.

Casebolt, D.B., Qian, B. and Stephenso, C.B. (1992). Detection of enterotropic mousehepatitis virus in fecal excretion by polymerase chain reaction. Laboratory animal science. 47(1): 6-10.

Elizabeth, F.M., Rasmussen, L., Fung, P., Amanda, M.A., Luisana, A., David, A.L., Morgan, E.Q., Tammy, D.D., Gloria, M.D. F. and Bianca, A.V. (2012). Prevalence of viral, bacterial and parasitological diseases in rats and mice used in research environments in Australia over a5-y period. Lab Animal Asia Pacific. 3: 4-14.

Kohale, K.N. and Raut, C.G. (2013). Sero-monitoring of common pathogens in various species of laboratory animals at the animal facilities of two research institutes. Indian J. Compo Microbiol. Immunol. Infect. Dis. 34(2): 44-50.

Kundave, V.R., Ram, H., Rafiqi, S.I., Garg, R., Tiwari, A.K. and Benerjee, P.S. (2017). Comparative evaluation of microscopy and PCR assay for detection of Theileria Annulata infections in Ruminants. Journal of Animal Research. 7(4): 699-703.

Nicklas, W., Homberger, F.R., Brunhilde, I.W., Jacobi, K., Kraft, V. and Kunstyr, I. (1999). Implications of infectious agents on results of animal experiment. Lab Anim. 33(1): 39-87.

Pritchett-Corning, K.R., Cosentino, J. and Clifford, C.B. (2009). Contemporary prevalence of infectious agentsin laboratory mice and rats. Lab Anim. 43(2): 165-173.
Pullium, J.K., Homberger, F.R., Benjamin, K.A., Dillehay, D.L. and Huerkamp, M.J. (2003). Confirmed persistent mouse hepatitis virus infection and transmission by mice with a targeted null mutation of tumour necrosis factor to sentinel mice, Using short-term exposure. Comparitive medicine. 53(4): 439-443

Scavizzi, F. and Raspa, M. (2004). Tissue distribution and duration of mouse hepatitis virus in naturally infected immunocompetent ICR (CD-1) and immunodeficient athymic nude-nu mouse strains used for ovarian transplantation and in vitro fertilization. Lab Anim. 38: 189-199.

Homberger, F.R., Zhang, L. and Barthold, S.W. (1998). Prevalence of Enterotropic andPolytropic Mouse Hepatitis Virus in Enzootically Infected Mouse Colonies. Lab Anim Sci. 48(1): 50-54.

Wan, C.H., Bauer, B.A., Pintel, D.J. and Riley, L.K. (2006). Detection of rat parvovirus type 1 and rat minute virus type 1 by polymerase chain reaction. Lab Anim. 40(1): 63-69.

Wang, R.F., Campbell, W.L., Cao, W.W., Colvert, R.M., Holland, M.A. and Cerniglia, C. E. (1999). Diagnosis of mouse hepatitis virus contamination in mouse population by using nude mice and RT-PCR. Mol cell Probes. 13(1): 29-33.

Yamada, Y.K., Yabe, M., Takimatoo, K., Nakayama, K. and Saitoh, M. (1998). Application of Nested Polymerase chain reaction to detection of Mouse Hepatitis Virus in Fecal Specimens during Natural Outbreak in an Immunodeficient Mouse Colony. Exp. Anim. 47(4): 261-264. 